\title{
Performance and design optimization of a low-cost solar organic Rankine cycle for remote power generation
}

\author{
S. Quoilin ${ }^{\mathrm{a}, *}$, M. Orosz ${ }^{\mathrm{b}}, \mathrm{H}$. Hemond $^{\mathrm{b}}$, V. Lemort ${ }^{\mathrm{a}}$ \\ ${ }^{a}$ Thermodynamics Laboratory, University of Liège, Campus du Sart Tilman, B49, B-4000 Liège, Belgium \\ ${ }^{\mathrm{b}}$ Department of Civil and Environmental Engineering, Massachusetts Institute of Technology (MIT), 15 Vassar St. 48-216, Cambridge, MA 02139, USA
}

Received 7 December 2010; received in revised form 10 February 2011; accepted 15 February 2011

Communicated by: Associate Editor R. Petela

\begin{abstract}
Recent interest in small-scale solar thermal combined heat and power (CHP) power systems has coincided with demand growth for distributed electricity supplies in areas poorly served by centralized power stations. One potential technical approach to meeting this demand is the parabolic trough solar thermal collector coupled with an organic Rankine cycle (ORC) heat engine.

The paper describes the design of a solar organic Rankine cycle being installed in Lesotho for rural electrification purpose. The system consists of parabolic though collectors, a storages tank, and a small-scale ORC engine using scroll expanders.

A model of each component is developed taking into account the main physical and mechanical phenomena occurring in the cycle and based on experimental data for the main key components.

The model allows sizing the different components of the cycle and evaluates the performance of the system. Different working fluids are compared, and two different expansion machine configurations are simulated (single and double stage).

(C) 2011 Elsevier Ltd. All rights reserved.
\end{abstract}

Keywords: Organic Rankine cycle; ORC; Solar concentrator; Parabolic trough; Rural electrification; Concentrating solar power

\section{Introduction}

Concentrating Solar Power (CSP) systems have been implemented with a variety of collector systems such as the parabolic trough, the solar dish, the solar tower or the Fresnel linear collector. However, most of the currently installed CSP plants use a steam Rankine cycle in the power block. This technology requires a minimum power of a few MWe in order to be competitive and involves high collector temperatures.

Particularly in the case of small-scale systems, an organic Rankine cycle (i.e. a Rankine cycle using an organic fluid instead of water) may show a number of advantages over the steam cycle. These include a lower working temperature,

\footnotetext{
* Corresponding author. Tel.: +1 32436648 22; fax: +1 3243664812 . E-mail address: squoilin@ulg.ac.be (S. Quoilin).
}

the absence of droplets during the expansion, the low maintenance requirements and the simplicity (fewer components). According to McMahan (2006), those advantages make the ORC technology more economically attractive when used at small and medium power scales.

Solar ORCs have been studied both theoretically (Davidson, 1977; Probert et al., 1983) and experimentally (Monahan, 1976) as early as in the 1970s and with reported overall efficiencies varying between $2.52 \%$ and $7 \%$. Experimental studies usually involved the use of vane expanders (Badr et al., 1985 multi-vane expanders, Davidson, 1977), and high Ozone Depleting Potential (ODP) refrigerants such as R11 or R13 were often used. Recent studies have tended to emphasize optimization of fluid selection for different cycle architectures and collecting temperatures (Wolpert and Riffat, 1996; McMahan, 2006; DelgadoTorres and Garcia-Rodriguez, 2007, 2010; Bruno et al., 


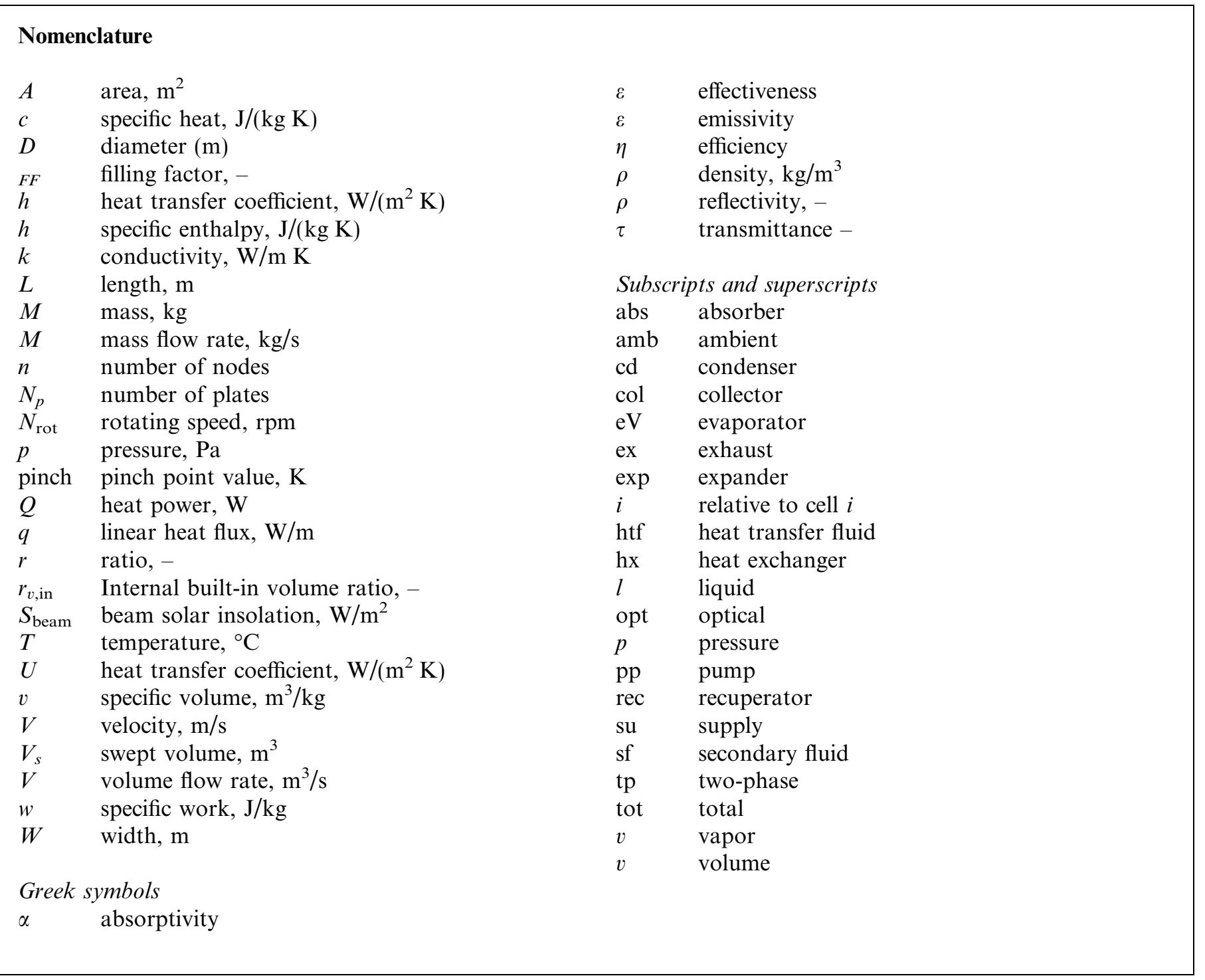

2008; Wang et al., 2010a). It is interesting to note, however, that no single fluid has been identified as optimal for the ORC. This is mainly due to the strong interdependence between the optimal working fluid, the working conditions and the cycle architecture. It follows that the study of the working fluid candidates should be integrated into the design process of any ORC system.

Few studies have provided experimental data from operational solar ORC systems: Kane et al. (2003) studied the coupling of linear Fresnel collectors with a cascaded 9kWe ORC, using R123 and R134a as working fluids. An overall efficiency (solar to electricity) of $7.74 \%$ was obtained, with a collector efficiency of $57 \%$. Manolakos et al. (2007) studied a $2 \mathrm{kWe}$ low-temperature solar ORC with R134a as working fluid and evacuated tube collectors: an overall efficiency below 4\% was obtained. Wang et al. (2010b) studied a $1.6 \mathrm{kWe}$ solar ORC using a rolling piston expander. An overall efficiency of $4.2 \%$ was obtained with evacuated tube collectors and 3.2\% with flat-plate collectors. The difference in terms of efficiency was explained by lower collector efficiency ( $71 \%$ for the evacuated tube vs. $55 \%$ for the plate technology) and lower collection temperature.

Detailed models of such systems are also scarce in the scientific literature: McMahan (2006) proposed a detailed model and an optimization of the ORC cycle for solar applications, but this model was not coupled to a solar collector model; Forristall (2003) proposed a model of the solar collectors validated with the SEGS plants data, independent of a power cycle model. Jing et al. (2010) developed a model of an ORC cycle using R123 as working fluid and coupled to CPC collectors: the predicted overall efficiency was about $7.9 \%$ for a solar insolation of $800 \mathrm{~W} / \mathrm{m}^{2}$ and an evaporating temperature of $147^{\circ} \mathrm{C}$. Kane (2002) developed a model of a cascaded ORC using scroll expanders and coupled to a collector model. This model was used to conduct a thermoeconomic optimization on the system.

Most of the above mentioned studies show that the ORC efficiency is significantly improved by inclusion of a 
recuperator, of cascaded cycles, or of reheating (McMahan, 2006; Kane et al., 2003; Prabhu, 2006).

At present, only one commercial solar ORC power plant is reported in the technical literature: the $1 \mathrm{MWe}$ Saguaro Solar ORC plant in Arizona, USA. This plant uses $n$-pentane as working fluid and shows an overall efficiency of $12.1 \%$, for a collector efficiency of 59\% (Canada et al., 2004).

If medium-scale solar ORCs are already commercially available, work remains to be done for very small-scale units (a few $\mathrm{kWe}$ ), especially to reduce the specific investment costs and to control the system in order to avoid the need of an on-site operator.

\section{System description}

Researchers at MIT and University of Liège have collaborated with the non-governmental organization STG International for the purpose of developing and implementing a small-scale solar thermal technology utilizing medium temperature collectors and an ORC. A first unit was installed by STG in 2007, and is shown in Fig. 1.

The goal is to provide rural areas of developing countries with a system that can be manufactured and assembled locally (unlike PV collectors) and can replace or supplement Diesel generators in off-grid areas, by generating clean power at a lower levelized cost (Orosz et al., 2010).

At the core of this technology is a solar thermal power plant consisting of a field of parabolic solar concentrating collectors and a vapor expansion power block for generating electricity. An electronic control unit is added for autonomous operation as sub-megawatt scale plants cannot justify the staffing of operating personnel. Operating at a lower cycle temperatures $\left(<200{ }^{\circ} \mathrm{C}\right)$ and Carnot efficiency is an example of a design tradeoff for maintaining low cost at small scales. For a given level of output power, lower temperatures enable cost savings in the materials and

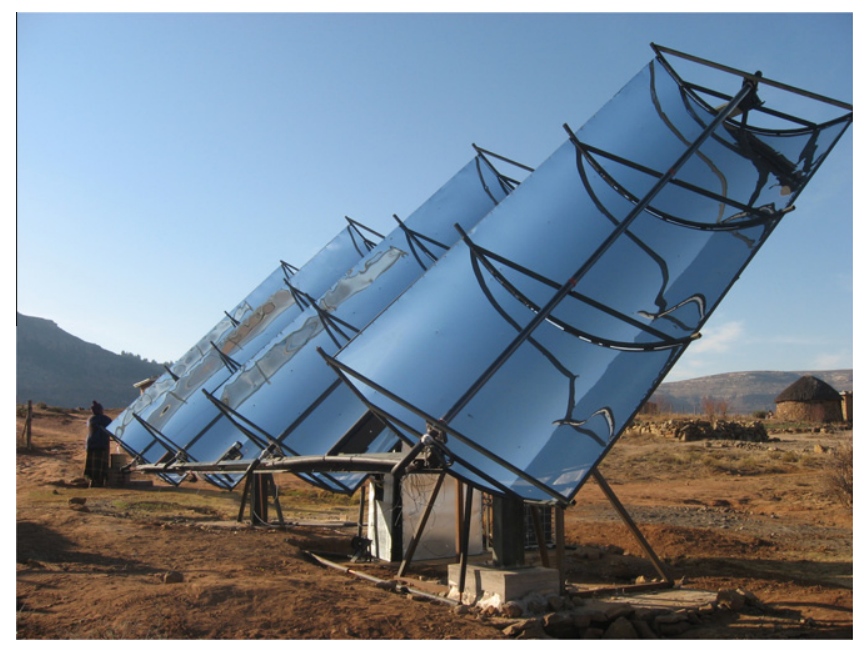

Fig. 1. Solar ORC prototype installed by STG in Lesotho. manufacture of the absorber units, heat exchangers, fluid manifolds and parabolic troughs.

Because no thermal power blocks are currently manufactured in the kilowatt range a small-scale ORC has to be designed for this application. The design is based on modified commercially available components e.g. HVAC scroll compressors (for the expander), and industrial pumps and heat exchangers. It should be noted that the main challenge for ORC development is the high cost of specially designed expander-generator equipment. At present, no volumetric expander is available on the market. In order to reduce the cost of a practicable system, the expander is obtained by adapting an off-the-shelf hermetic scroll compressor to run in reverse, as proposed and successfully tested by Lemort et al. (2009a). Scroll machines show the advantage of being widely available, reliable and with a limited number of moving parts (Zanelli and Favrat, 1994).

The goal of this paper is to design and dimension an improved solar ORC unit to be installed in a rural clinic in Berea District of Lesotho and to evaluate its performance with different working fluids. The main characteristics of this unit are the following:

- Target net output power: $3 \mathrm{kWe}$

- Collector field: $75 \mathrm{~m}^{2}$ single-axis parabolic trough, using Miro aluminum reflectors and a Heat Collection Element (HCE) with selective coating and air-filled annulus between absorber pipe and glazing.

- ORC: One or two-stage expansion of R245fa using modified commercial HVAC compressors, brazed plate heat exchangers for high pressure heat transfer, and commercial HVAC tubes-and-fins air condenser for heat rejection.

- Heat transfer fluid (HTF): Monoethylene glycol (MEG) with thermal buffering in a thermal storage tank with a $2 \mathrm{~m}^{3}$ packed bed of $19 \mathrm{~mm}$ quartzite.

The heat transfer fluid is heated up in the collector field and driven to the evaporator by the heat transfer fluid pump. A thermal storage is installed in order to attenuate the fast fluctuations of solar irradiation during the day and to maintain stable operation of the ORC engine (see Fig. 2).

The main components in the classical Rankine cycle include an evaporator, expander, a condenser and a recirculation pump. In an ORC with a 'dry' fluid, recuperation from the superheated exhaust to the subcooled liquid is typically achieved with a heat exchanger interposed between the expander exhaust and the pump outlet. This superheated exhaust is also readily exploitable for cogeneration, requiring an additional heat exchanger which can be positioned in series with or parallel to the recuperator.

In the proposed system the cycle heat exchangers (evaporator, recuperator and condenser) are sized in order to obtain the required pinch point and pressure drop. The working fluid is condensed in an air condenser in order to avoid unnecessary water consumption (but at the 


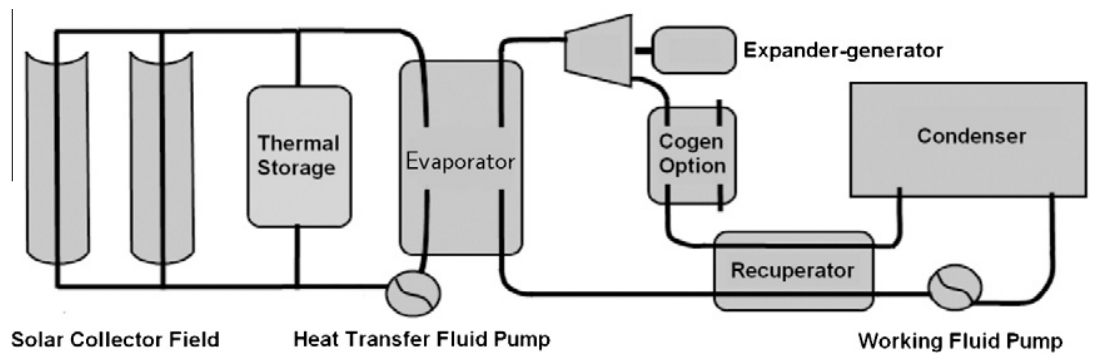

Fig. 2. Conceptual scheme of the solar ORC.

expense of non-negligible fan consumption) and then repressurized in a piston pump The expansion process is performed by one or two modified HVAC scroll machines configured in series. Cogeneration is obtained with the additional plate heat exchanger installed between the expander and the recuperator in order to produce hot water in addition to electricity, depending on the local demand.

\section{Modeling}

In this section, a steady-state model of the system presented in Fig. 2 is developed, for the rating and sizing of the different components and to optimize the working conditions on a nominal point. The transient behavior of the solar source is not taken into account here and an average insolation is utilized. It is assumed that the storage is sized in such a way to maintain almost constant heat transfer fluid flow rate and temperature during the operating time of the system: the ORC engine is assumed to stand by in case of insufficient solar insolation for meeting temperature requirements and in order to avoid part-load conditions that might reduce the cycle efficiency. In practice this means that during periods of low insolation, the time to charge the storage to the set operational point is longer than the operating time of the ORC engine. In light of this steady state hypothesis, the storage tank is not modeled. The water heating heat exchanger is also neglected, since the main goal of the model is to evaluate the electricity generation potential of the system.

The solar ORC is model within the EES environment (Klein, 2010): a model is developed for each subcomponent and included into a module. These modules are further interconnected to obtain the global model of the system.

The proposed global model cannot be validated experimentally because of the lack of experimental data. However, it was shown in a previous publication that connecting validated component submodels in order to build a global ORC model can lead to an acceptable overall error lower than $10 \%$ compared to experimental data (Quoilin et al., 2010).

Since a nominal size (or power) must be set, the proposed model is a hybrid between a simulation model and a sizing model: on one hand, the design, the size and the parameters of the collector are set according to the collector technology developed by STG International and installed in Lesotho. On the other hand, the size of the ORC cycle and of its components is recalculated by the model in order to obtain a good match between collector power and ORC engine power.

\subsection{Parabolic trough model}

The trough module, largely adapted from Forristall (2003), is a one-dimensional energy balance model around a Heat Collection Element (HCE) of user specified dimensions and materials: Radiation impinges on a reflector element with user-input focal length, reflective coefficient, and aperture. The energy is correspondingly reduced (e.g. due to a reflective coefficient $<1$ ) and concentrated onto a nodal area of the HCE, where it is transmitted through a glass envelope and a gas annulus, and finally absorbed or reflected at the surface of the HCE.

Depending on the absorptivity and emissivity characteristics of the selective coating and the temperature of the HTF flowing through the HCE at a given node, some amount of absorbed energy is transferred through the HCE wall into the HTF (process $2-1$ in Fig. 3) with a heat exchange coefficient calculated from the fluid thermal properties and flow regime parameters. The remaining absorbed heat is lost at the HCE outer surface, via convection and radiation back through the annulus (process 3-4), conduction through the envelope (process 4-5), radiation between

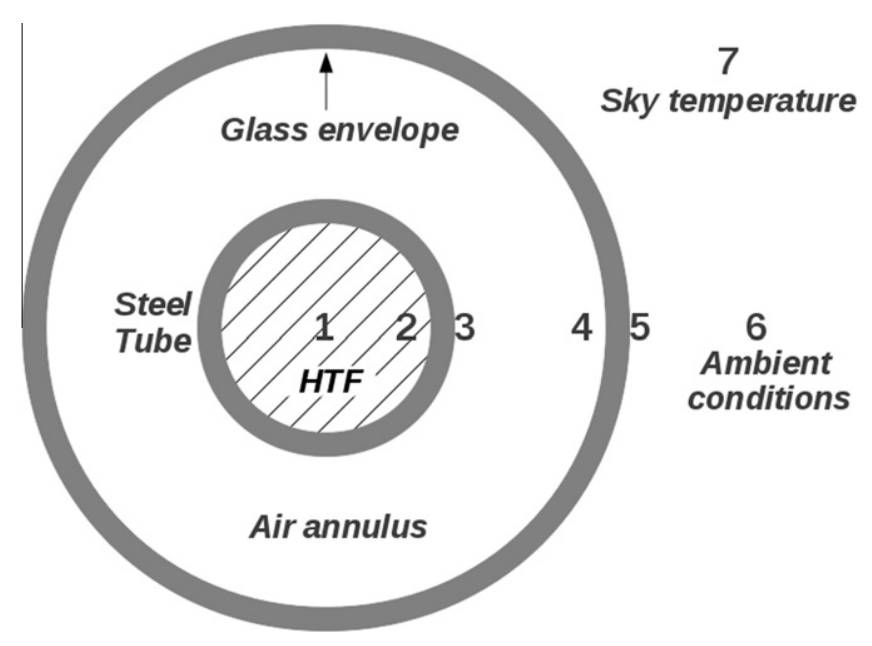

Fig. 3. Heat transfer in the absorber. 
the envelope and the sky (process 5-7) and convection to the ambient air (process 5-6).

This process is repeated for each node, where the input for each node is the output of the previous node, resulting in an overall enthalpy and temperature gain for the focal line length specified by the user. The collector module thus derives a thermal efficiency and outputs a heat flux and temperature gain for the HTF at the user specified flow rate and initial temperature.

The different heat transfer relations used to compute the heat flows are provided in Table 1.

The amounts of radiation absorbed by the collector and by the glass enveloped are respectively given by (Forristall, 2003):

$q_{\text {sun }, 3}=q_{\text {sun }} \cdot \eta_{\text {opt }} \cdot \tau_{\text {env }} \cdot \alpha_{\text {coating }}$

$q_{\mathrm{sun}, 5}=q_{\mathrm{sun}} \cdot \eta_{\mathrm{opt}} \cdot \alpha_{\mathrm{env}}$

where $q_{\text {sun }}=S \cdot W_{\text {col }}$ is the linear beam insolation.

And

$\eta_{\text {opt }}=\rho_{\text {mirror }} \cdot \eta_{\text {shadowing }} \cdot \eta_{\text {geomery }} \cdot \eta_{\text {unaccounted }}$

$\eta_{\text {opt }}$ is the optical efficiency, lumping different sources of losses such as mirror reflectivity $\left(\rho_{\text {mirror }}\right)$, tracking losses $\left(\eta_{\text {tracking }}\right)$, shadowing $\left(\eta_{\text {shadowing }}\right)$, geometrical effects $\left(\eta_{\text {geometry }}\right.$ and other unaccounted losses $\left(\eta_{\text {unaccounted }}\right)$. The values of the different efficiencies are the ones recommended by Forristall (2003), except for $\eta_{\text {tracking }}$ and $\eta_{\text {geometry }}$, where a significantly lower efficiency is selected. This conservative hypothesis is made in order to account for the relatively lower optical intercept factor $(\sim 0.9)$ resulting from the low-cost design of the collector, which could reduce the performance of the system.

In order to reduce the magnitude of $q_{34, \text { rad }}$, a selective coating is applied on the collector tube, maximizing the solar absorptivity and minimizing the infra-red emissivity. This emissivity is calculated according to Forristall recommendation for a "Solar UAV cermet" coating:

$\varepsilon_{\text {coating }}=2.249 \cdot 10^{-7} \cdot T_{3}^{2}+1.039 \cdot 10^{-4} \cdot T_{3}+5.599 \cdot 10^{-2}$

For each cell of the discretized collector (having a length equal to the total focal line length divided by the number of nodes) the different energy balance equations can be applied:

$T_{\text {ex,cell }}=T_{\text {su,cell }}+\frac{q_{12} \cdot \Delta x}{M_{\mathrm{htf}} \cdot \bar{c} p_{\mathrm{htf}}}$

$q_{45}=q_{34, \mathrm{conv}}+q_{34, \mathrm{rad}}$

$q_{56, \mathrm{conv}}=q_{45}+q_{\mathrm{sun}, 5}-q_{57}$

$q_{12, \mathrm{conv}}=q_{23}$

$q_{23}+q_{34, \mathrm{conv}}+q_{34, \mathrm{rad}}-q_{\mathrm{sun}, 3}=0$

Moreover, a pressure drop in the heat transfer fluid can be computed in each cell using the following equation:

$\Delta p_{\text {cell }}=\frac{f \cdot \Delta L \cdot G_{\mathrm{htf}}^{2}}{2 \cdot D_{2} \cdot \rho}$

where $f$ is the friction factor, calculated with the Gnielinski correlation (Incropera and Dewitt, 2002).

The different parameters used for the modeling of the solar collected are summarized in Table 2.

\subsection{Evaporator model}

The evaporator is modeled by means of the Logarithmic Mean Temperature Difference (LMTD) method for

Table 2

Collector model parameters.

\begin{tabular}{lll}
\hline Parameter & Description & Value \\
\hline$\rho_{\text {mirror }}$ & Mirror reflectivity & 0.94 \\
$\eta_{\text {tracking }}$ & Tracking error & 0.92 \\
$\eta_{\text {shadowing }}$ & Shadowing error & 0.98 \\
$\eta_{\text {geometry }}$ & Geometry error & 0.93 \\
$\eta_{\text {unaccounted }}$ & Unaccounted losses & 0.96 \\
$D_{2}$ & Absorber tube inner diameter & $66 \mathrm{~mm}$ \\
$D_{3}$ & Absorber tube outer diameter & $70 \mathrm{~mm}$ \\
$D_{4}$ & Envelope inner diameter & $80 \mathrm{~mm}$ \\
$D_{5}$ & Envelope outer diameter & $88 \mathrm{~mm}$ \\
$L_{\text {col }}$ & Total collector length & $46 \mathrm{~m}$ \\
$W_{\text {col }}$ & Collector width & $2.5 \mathrm{~m}$ \\
$\tau_{\text {env }}$ & Envelope transmissivity & 0.96 \\
$\alpha_{\text {env }}$ & Envelope absorptivity & 0.04 \\
$\alpha_{\text {coating }}$ & Coating absorptivity & 0.96 \\
$\varepsilon_{\text {env }}$ & Envelope emissivity & 0.86 \\
$N$ & Number of node & 15 \\
\hline
\end{tabular}

Table 1

Absorber heat transfer models.

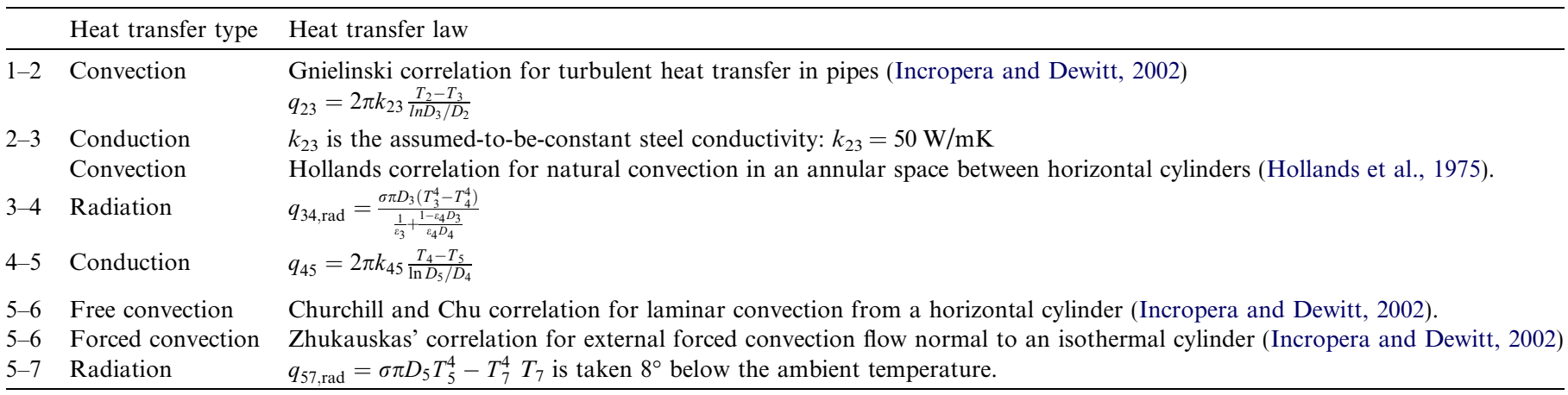


counter-flow heat exchangers. The heat exchanger is subdivided into three moving-boundaries zones, each of them being characterized by a heat transfer area $A$ and a heat transfer coefficient $U$ (Quoilin et al., 2010).

The heat transfer coefficient $U$ is calculated by considering two convective heat transfer resistances in series (secondary fluid and refrigerant sides).

$\frac{1}{U}=\frac{1}{h_{r}}+\frac{1}{h_{\mathrm{sf}}}$

The total heat transfer area of the heat exchanger is given by:

$A_{\mathrm{tot}}=A_{l}+A_{t p}+A_{v}=\left(N_{p}-2\right) \cdot L \cdot W$

$N_{p}$ being the number of plates, $L$ the plate length and $W$ the plate width.

\subsubsection{Single-phase}

Forced convection heat transfer coefficients are evaluated by means of the non-dimensional relationship:

$\mathrm{Nu}=C \operatorname{Re}^{m} \operatorname{Pr}^{n}$

where the influence of temperature-dependent viscosity is neglected.

The parameters $\mathrm{C}, m$ and $n$ are set according to Thonon's correlation for corrugated plate heat exchangers (Thonon et al., 1995).

The pressure drops are computed with the following relation:

$\Delta p=\frac{2 \cdot f \cdot G^{2}}{\rho \cdot D_{h}} \cdot L$

where $f$ is the friction factor, calculated with the Thonon correlation, $\mathrm{G}$ is the mass velocity $\left(\mathrm{kg} / \mathrm{s} \mathrm{m}^{2}\right), \rho$ is the mean fluid density, $D_{h}$ is the hydraulic diameter and $L$ is the plate length.

\subsubsection{Boiling heat transfer coefficient}

The overall boiling heat transfer coefficient is estimated by the Hsieh correlation, established for the boiling of refrigerant R410a in a vertical plate heat exchanger. This heat exchange coefficient is considered as constant during the whole evaporation process and is calculated by (Hsieh and Lin, 2003):

$h_{t p}=C h_{l} B o^{0.5}$

where $B o$ is the boiling number and $h_{l}$ is the all-liquid nonboiling heat transfer coefficient.

The pressure drops are calculated in the same manner as in Eq. (14), using the Hsieh correlation for the calculation of the friction factor.

\subsubsection{Heat exchanger sizing}

For a given corrugation pattern (amplitude, chevron angle, and enlargement factor), two degrees of freedom are available when sizing a plate heat exchanger: the length and the total flow width. The total flow width is given by the plate width multiplied by the number of channels:
$W_{\mathrm{tot}}=W_{\mathrm{hx}} \cdot \frac{N_{p}-1}{2}$

The two degrees of freedom are fixed by the heat exchange area requirement and the limitation on the pressure drop on the working fluid side:

- Increasing the total width decreases the Reynolds number. This leads to a lower pressure drop and to a higher required heat transfer area, since the heat transfer coefficient is also decreased.

- Increasing the plate length leads to a higher pressure drop.

Therefore, by imposing a pinch point and a pressure drop, it is possible to define the total width and the length of the plate heat exchanger. The flow chart of the sizing process is shown in Fig. 4.

The imposed parameters of the evaporator model are presented in Table 3.

\subsection{Recuperator model}

The recuperator model is similar to the evaporator model, with one zone (single-phase) instead of three. The

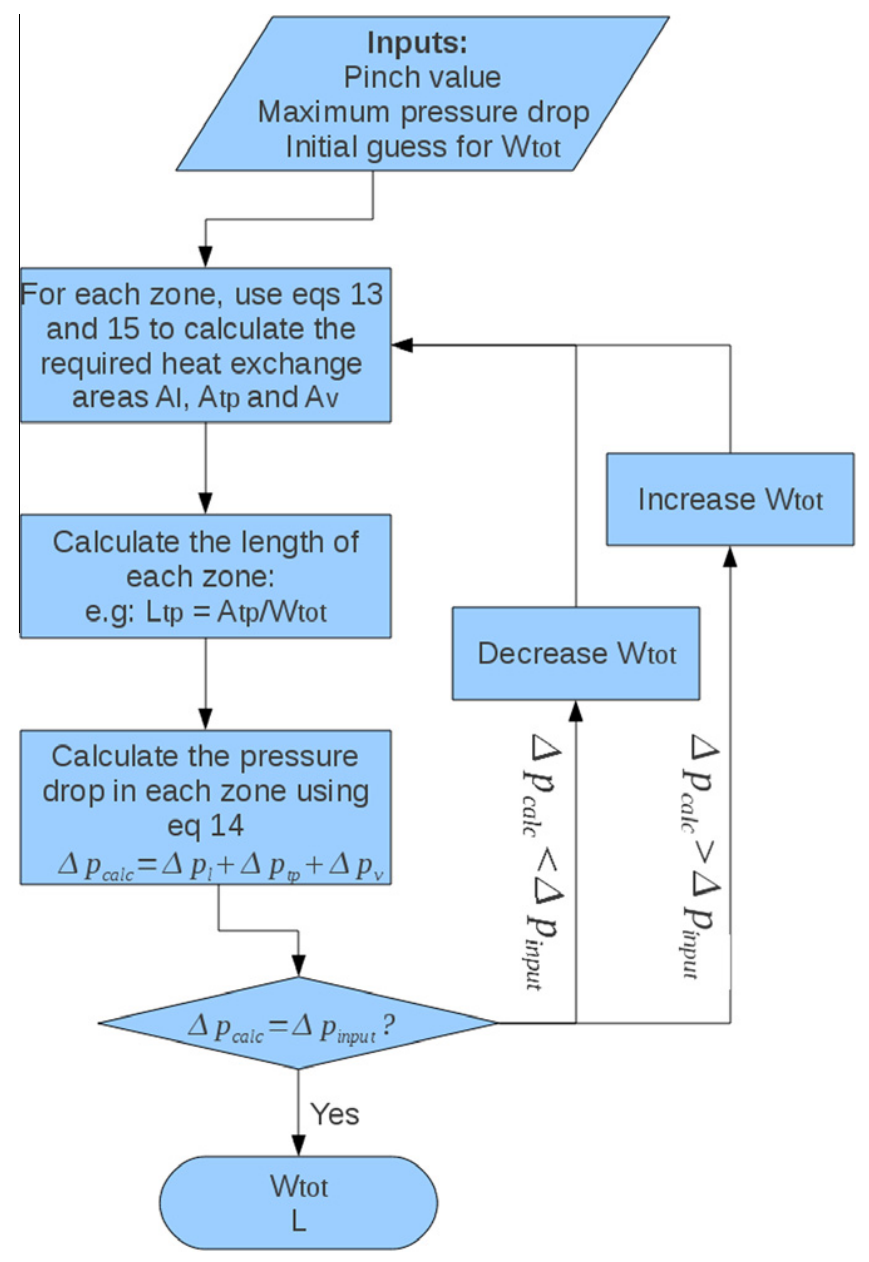

Fig. 4. Plate heat exchangers sizing process 
Table 3

Evaporator model parameters.

\begin{tabular}{lll}
\hline Parameter & Description & Value \\
\hline$D_{h}$ & Hydraulic diameter & $2 \mathrm{~mm}$ \\
$\beta_{\text {chevron }}$ & Chevron angle & $45^{\circ}$ \\
\hline
\end{tabular}

inputs of the model are the maximum pressure drop and the heat exchanger efficiency, which allows sizing the exchanger in terms of total width and length.

\subsection{Expander model}

Volumetric expanders, such as the scroll, screw or reciprocating technologies present an internal built-in volume ratio $\left(r_{v, \text { in }}\right)$ corresponding to the ratio between the inlet pocket volume and the outlet pocket volume. This can generate two types of losses if the system specific volume ratio is not equal to the expander nominal volume ratio:

Under-expansion occurs when the internal volume ratio of the expander is lower than the system specific volume ratio. In that case, the specific volume in the expansion chambers at the end of the expansion process $\left(P_{\text {in }}\right)$ is lower than the specific volume in the discharge line.

Likewise over-expansion occurs when the internal volume ratio imposed by the expander is higher than the system specific volume ratio.

These two effects can considerably reduce the efficiency of the expansion process. Other sources of losses include friction losses, supply pressure drop, internal leakage and heat transfers (Lemort et al., 2009a,b).

Since no off-the-shelf small-scale expansion machine is currently available on the market, the expander was obtained by modifying a scroll compressor to make it run in reverse. This allows keeping the expander cost low, hermetic compressors being very common components in HVAC applications. On the other hand, since the device is not optimized for expander applications, experimental results by Lemort et al. showed that the efficiency is reduced by about $10 \%$ when working in expander mode (about $60 \%$ efficiency) compared to the compressor mode (typically $70 \%$ ). In this work, the considered expander is a hermetic scroll expander tested and modeled by Lemort et al. (2009b).

A semi-empirical thermodynamic model such as the one proposed by Lemort et al. is not suitable for the purpose of this work since it was developed for one machine in particular. Here, a sizing model is needed, that can predict the performance of scroll expanders with very different swept volumes.

If ambient heat losses are neglected, scroll expanders can be modeled by their isentropic efficiency and by their filling factor, respectively defined by (Lemort et al., 2009b):

$\varepsilon_{\exp }=\frac{W_{\text {exp }}}{M \cdot\left(h_{\mathrm{su}, \exp }-h_{\mathrm{ex}, \exp , s}\right)}$ and

$$
F F=\frac{60 \cdot M}{\rho_{\text {su }} \cdot V_{s} \cdot N_{\text {rot }}}
$$

where $V_{\mathrm{s}}$ is the swept volume of the expander and $N_{\text {rot }}$ its rotational speed (assumed-to-be-constant at $3000 \mathrm{rpm}$ ). where $W_{\exp }$ is the electrical power generated by the expander and $h_{\text {ex,exp,s }}$ is the isentropic exhaust enthalpy. It should be noted that the given efficiency is an electrical and not a mechanical isentropic efficiency (i.e. electromechanical losses in the generator are accounted for).

In order to simulate realistic performance close to the actual experimental data, the model developed by Lemort et al. (2009b) is used to express $\varepsilon$ and $F F$ as a polynomial law of the main working conditions. The two selected working conditions are the fluid inlet density $\rho_{\text {su }}$ and pressure ratio over the expander $r_{p}$ since they turned out to be the two main representative variables of the working conditions. The polynomial fits are expressed in the following form:

$$
\begin{aligned}
\varepsilon & =\sum_{i=0}^{n-1} \sum_{j=0}^{n-1} a_{i j} \cdot \ln \left(r_{p}\right)^{i} \cdot \rho_{\mathrm{su}}^{j}+a_{0 n} \cdot \ln \left(r_{p}\right)^{n}+a_{0 n} \cdot \rho_{1}^{n} \\
& =f\left(r_{p}, \rho_{\mathrm{su}}\right)
\end{aligned}
$$

For $\varepsilon$, a 4th-order $(n=4)$ polynomial fit is used, while for $F F$ a second-order $(n=2)$ polynomial fit turned out to be sufficient. The correlations have been established on the basis of the validated model for 800 different working points inside of the following operating conditions:

$30<\rho_{\text {su }}<200 ; \quad 1.2<r_{p}<12$

The values of $\varepsilon$ and $F F$ were respectively predicted by the polynomial fit with $R^{2}=99.98 \%$ and $R^{2}=99.96 \%$.

It is assumed that, when changing the scale of the expander (and thus the swept volume), the isentropic efficiency and the filling factor remain similar if the pressure ratio and the inlet density are kept equal.

\subsubsection{Double-stage expander}

As mentioned above, volumetric expanders are optimized for a given specific volume ratio. It appears that the specific volume ratios involved in refrigeration for which the scroll compressors are designed is typically much lower than the specific volume ratios involved in ORC cycles. When the expander is obtained from a modified scroll compressor, under-expansion losses can therefore become prohibitive for high specific volume ratios (typically higher than 10). A possible solution consists in using two expanders assembled in series, as shown in Fig. 5.

When sizing a double-stage expander, it is important to define carefully the two swept volumes in order to optimize the intermediate pressure $\mathrm{p}_{2}$. If the expander efficiency was only dependent on the pressure ratio, the optimal singlestage pressure ratio would be defined as the square root of the overall pressure ratio $\left(r_{p, 1}=r_{p, 2}=\sqrt{r_{p}}\right)$ However, the efficiency also depends on the flow rate going through 


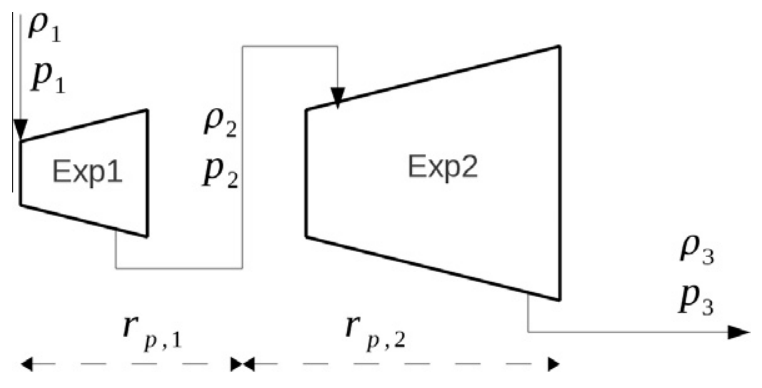

Fig. 5. Two-stage expander.

the expander because a higher flow rate entails a higher output power and makes the constant losses (e.g. friction losses) relatively smaller. In the polynomial correlations, the influence of the flow rate is reflected by the dependence in terms of supply vapor density.

In order to determine the optimal first-stage pressure ratio, the overall isentropic efficiency is maximized using the following equation:

$\frac{d \varepsilon}{d r_{p, 1}}=\frac{d}{d r_{p, 1}}\left[\frac{h_{1}-h_{3}}{h_{1}-h_{3 s}}\right]=0$

This can be done numerically or analytically. For the latter solution, $\varepsilon$ must be expressed in terms of $r_{p, 1}$, which can be achieved using the ideal gas hypothesis.

\subsection{Condenser model}

Since air condensers are well-known components in HVAC applications, a simplified model based on manufacturer data (Witt, 2004) is used to compute the condenser performance and fan consumption.

The two inputs are the pinch point, defined as the difference between the condensing temperature and the ambient temperature, and the condensing power.

Special attention is paid to the fan consumption since it can amount for a non-negligible share of the generated power. The fan consumption is computed as a function of the heat transfer power and of the pinch point with the following relation:

$W_{\text {fan }, \mathrm{cd}}=54.5+0.0185 \cdot Q_{\mathrm{cd}} \cdot \frac{8.333}{\text { pinch }_{\mathrm{cd}}}$

\subsection{Pumps model}

Two pump consumptions are taken into account: the heat transfer fluid pump and the working fluid pump. They are modeled by their isentropic efficiency, defined by (Quoilin et al., 2010):

$\varepsilon_{\mathrm{pp}}=\frac{v_{\mathrm{su}, \mathrm{pp}} \cdot\left(p_{\mathrm{ex}, \mathrm{pp}}-p_{\mathrm{su}, \mathrm{pp}}\right)}{h_{\mathrm{ex}, \mathrm{pp}}-h_{\mathrm{su}, \mathrm{pp}}}$

For the HTF pump, the pressure difference is given by the sum of the pressure drops in the evaporator and in the collector.
A constant, realistic value of $70 \%$ is assumed for the pump efficiency (Lin, 2008).

\subsection{Cycle model}

The global model of the system is obtained by interconnecting each subcomponent model according to Fig. 6.

Several performance indicators can be defined.

The overall collector efficiency:

$\eta_{\mathrm{col}}=\frac{M_{\mathrm{htf}} \cdot \bar{c} p_{\mathrm{htf}} \cdot\left(T_{\mathrm{htf}, \mathrm{ex}, \mathrm{col}}-T_{\mathrm{htf}, \mathrm{su}, \mathrm{col}}\right)}{S_{\text {beam }} \cdot L_{\mathrm{col}} \cdot W_{\mathrm{col}}}$

The net electrical output power:

$W_{\text {net }}=W_{\text {exp }}-W_{\text {pp }}-W_{\text {fans }}-W_{\text {pp,htf }}$

The ORC cycle efficiency:

$\eta_{\mathrm{ORC}}=\frac{W_{\mathrm{net}}}{Q_{\mathrm{eV}}}$

The overall system efficiency:

$\eta_{\text {overall }}=\frac{W_{\text {net }}}{S_{\text {beam }} \cdot L_{\mathrm{col}} \cdot W_{\mathrm{col}}}=\eta_{\mathrm{col}} \cdot \eta_{\mathrm{ORC}}$

In this work, the pinch points are set to $8 \mathrm{~K}$, the superheating at the expander inlet is set to $10 \mathrm{~K}$, the subcooling at the condenser outlet is set to $5 \mathrm{~K}$, and the maximum pressure drop on the refrigerant side of each heat exchanger is set to 75 mbar.

\section{System performance and fluid comparison}

This section aims at understanding the influence of different cycle parameters on the system and to compare

\section{Collector parameters}

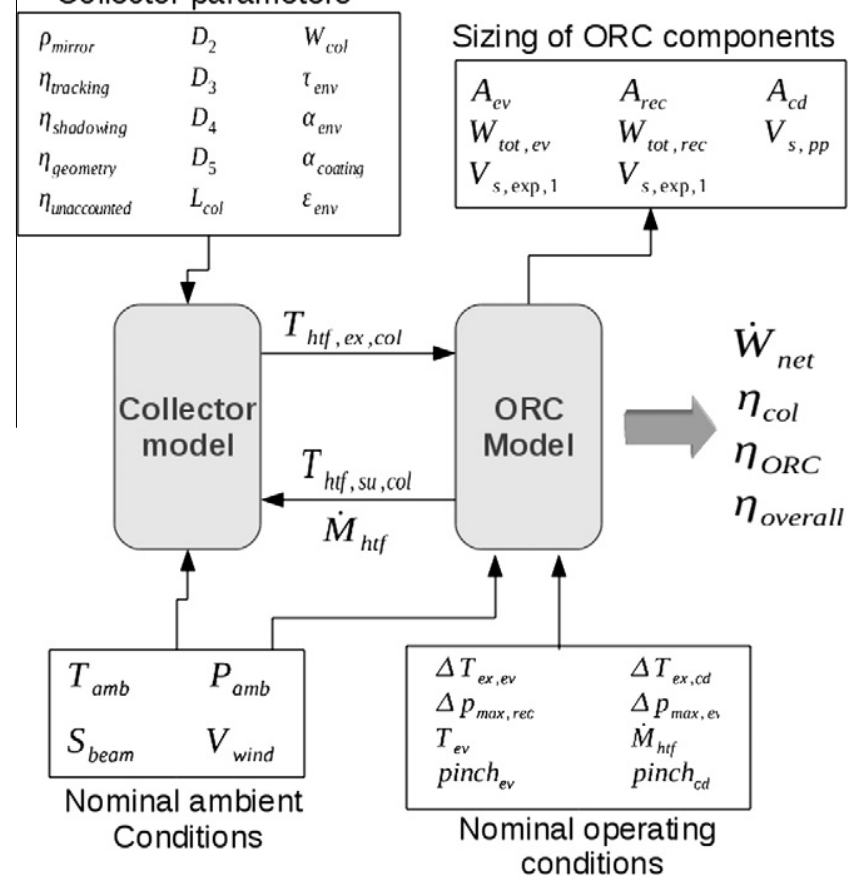

Fig. 6. Global model parameters, inputs and outputs. 
several working fluids and cycle architectures. For that purpose, nominal ambient conditions are imposed and are kept constant for all the simulations performed below:

$$
\begin{aligned}
& T_{\text {amp }}=15^{\circ} \mathrm{C} \\
& p_{\text {amp }}=0.83 \mathrm{bars} \\
& S_{\text {beam }}=800 \mathrm{~W} / \mathrm{m}^{2} \\
& V_{\text {wind }}=2 \mathrm{~m} / \mathrm{s}
\end{aligned}
$$

These conditions are typical of the mid-season or winter time conditions in the highlands of Lesotho.

Three main degrees of freedom are available to control the working conditions of the cycle: the heat transfer fluid flow rate, the working fluid flow rate and the expander swept volume or rotational speed. Setting the working fluid flow rate and the expander speed allows defining the evaporating temperature and the superheating (Quoilin et al., 2010). Setting the heat transfer fluid flow rate allows defining the temperature glide in the collector. According to Yamamoto et al. (2001), the superheating should be maintained as low as possible when using high molecular weight working fluids. The two remaining degrees of freedom (evaporating temperature and collector temperature glide) can be determined optimally, as shown in the next sections.

\subsection{Influence of the temperature glide in the collector}

Modifying the heat transfer fluid flow rate entails two main antagonist effects: on the one hand, the overall temperature level in the collector is modified (Fig. 7), which will impact its thermal efficiency via the various heat loss mechanisms.

On the other hand, changing the fluid flow rate affects the heat transfer coefficient between the heat transfer fluid and the absorber, which also impacts the collector efficiency.

Fig. 8 shows that the second effect is predominant: For very low temperature glides, the overall efficiency is reduced because of the very high HTF fluid pumping consumption. For high temperature glides, the overall

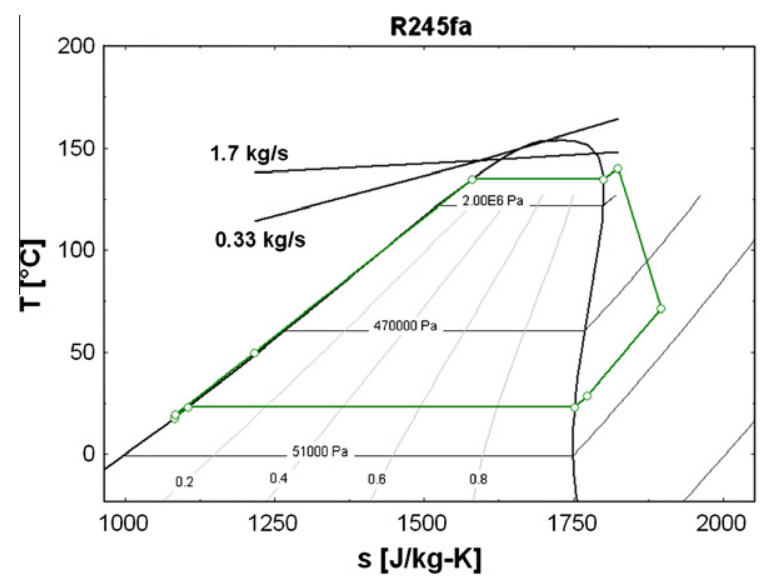

Fig. 7. $T-S$ diagram of the ORC process.

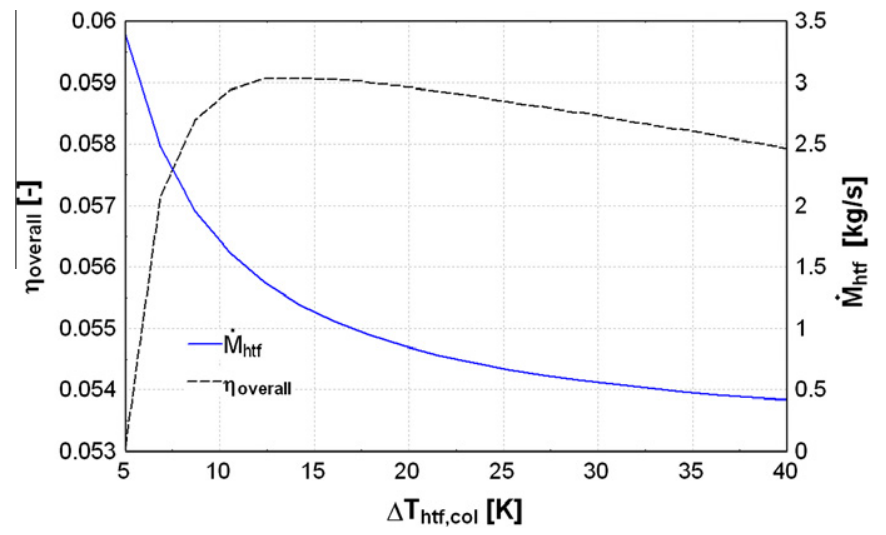

Fig. 8. Influence of the HTF temperature glide.

efficiency is lowered by the low heat transfer coefficient in the collector. An optimum is obtained for a temperature glide of $15 \mathrm{~K}$, corresponding to a heat transfer fluid flow rate of $1.2 \mathrm{~kg} / \mathrm{s}$.

In the following parametric studies, the temperature glide value will always be set to its optimal value for each computed working point. This value is obtained with the "Golden Section Search" algorithm.

\subsection{Influence of the evaporating pressure}

The selection of the optimal evaporating temperature results in a tradeoff between collector efficiency and cycle efficiency. In the particular case of an ORC using volumetric expanders, increasing the evaporation temperature also increases the under-expansion losses and reduces the cycle efficiency, which constitutes an additional influence.

The goal of this section is to illustrate the influence of the evaporating temperature on different cycle parameters and performance indicators. For that purpose, an arbitrary working point is selected: the selected working fluid is R245fa, with a two-stage expander, an optimized heat transfer fluid temperature glide, a superheating of $5 \mathrm{~K}$, and a subcooling of $5 \mathrm{~K}$.

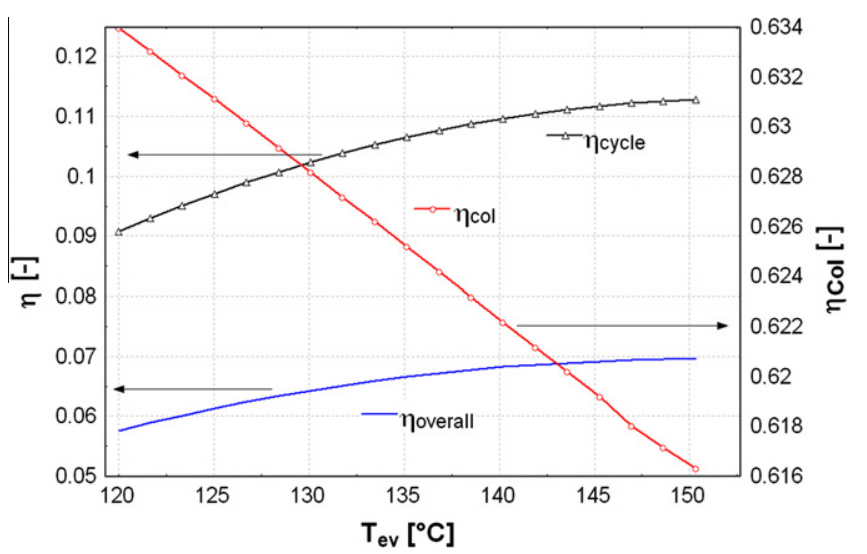

Fig. 9. Influence the evaporation temperature on the performance. 
As shown in Fig. 9, increasing the evaporating temperature leads to higher cycle efficiency and to lower collector efficiency. An optimal overall efficiency is stated around $150{ }^{\circ} \mathrm{C}$, which is just below the critical point $\left(154^{\circ} \mathrm{C}\right.$ for R245fa).

The evaporating temperature also has an impact on the size of the different components. Fig. 10 shows that with high evaporating temperature levels, smaller swept volumes are needed for both expanders since the inlet densities are higher. This is an appreciable advantage since the cost of the expanders is reduced.

A similar effect is stated for the heat transfer area of the evaporator (Fig. 11): for a given pressure drop, a higher vapor density allows reducing the passage area, which in turn reduces the required area. Fig. 11 also shows that a modification of the evaporating temperature has a very limited effect on the required recuperator area. Although those calculations were performed for R245fa, a similar behavior is stated for alternative working fluids.

\subsection{Working fluid and architecture comparison}

In order to compare a reasonable amount of working fluids, a pre-screening is performed with the following conditions:

- The critical point of the working fluid should be similar to the target temperature range $\left(100-200{ }^{\circ} \mathrm{C}\right)$.

- The working fluid should be a well known-fluid in stateof-the-art ORC applications or in the scientific literature dealing with working fluid selection (see Quoilin and Lemort (2009) for a review). This criterion ensures that several conditions such as the toxicity, the cost or the flammability are fulfilled.

- The working fluid should have a null Ozone Depleting Potential (ODP) in order to avoid the phasing-out of the Montreal Protocol.

Four fluids have been selected using this methodology: R134a, R245fa, Solkatherm (SES36) and $n$-pentane.

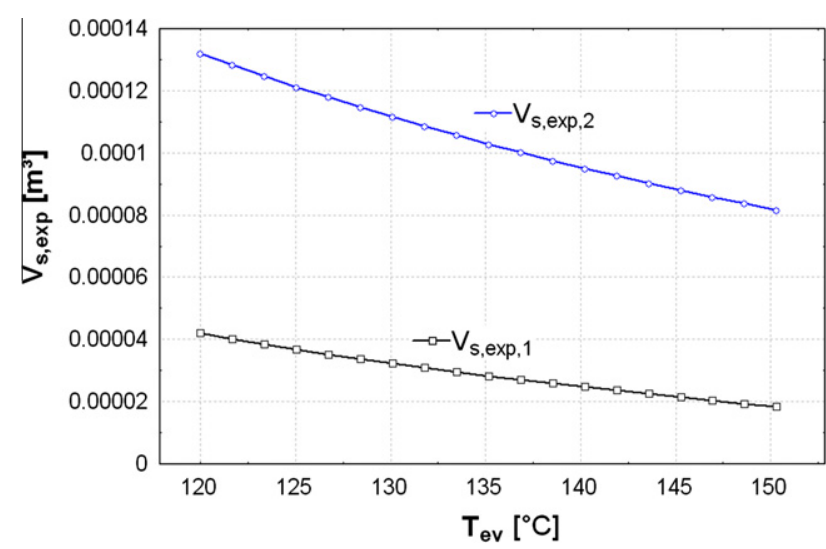

Fig. 10. Required swepts volumes vs. evaporating temperature.

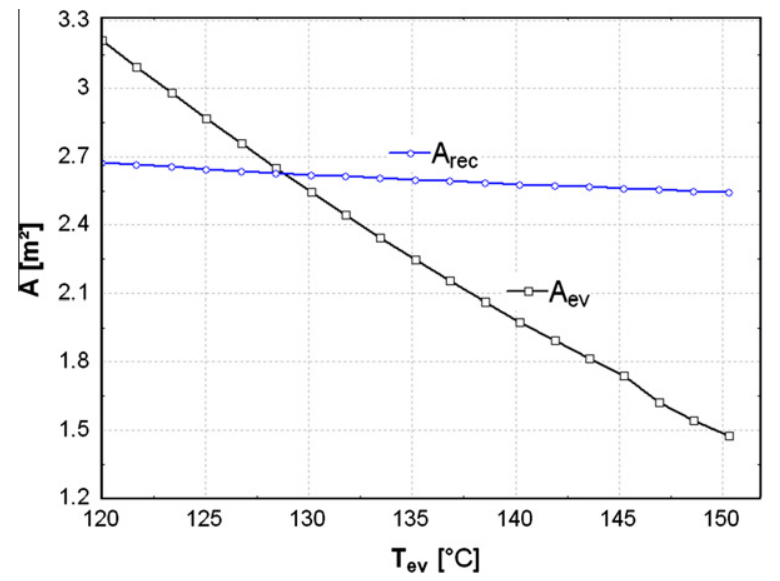

Fig. 11. Required heat transfer area vs. evaporation temperature.

One of the main influences of the working fluid on the cycle architecture lies in the specific volume ratio: generally speaking, the higher the critical temperature, the higher the specific volume ratio over the expander. The scroll expanders considered in this work are designed for a volume ratio close to 3. As discussed above, when used at much higher

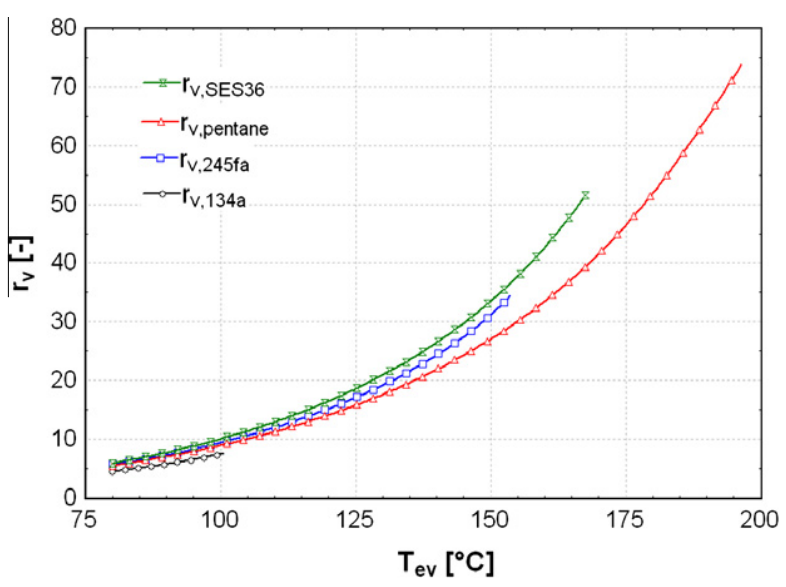

Fig. 12. Specific volume ratio vs. evaporation temperature.

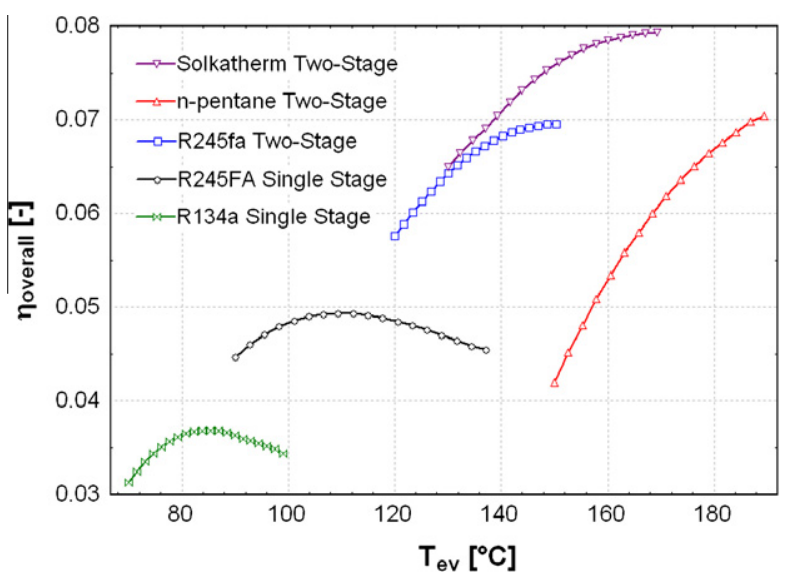

Fig. 13. Overall efficiency for different working fluids. 
Table 4

Simulations results for the different working fluids.

\begin{tabular}{|c|c|c|c|c|c|c|c|c|c|c|}
\hline & $T_{\mathrm{ev}}\left({ }^{\circ} \mathrm{C}\right)$ & $\Delta T_{\mathrm{HTF}}\left({ }^{\circ} \mathrm{C}\right)$ & $\eta_{\text {col }}(\%)$ & $\eta_{\text {ORC }}(\%)$ & $\eta_{\text {overall }}(\%)$ & $\varepsilon_{\exp }(\%)$ & $V_{s, 1}\left(\mathrm{~cm}^{3}\right)$ & $V_{s, 2}\left(\mathrm{~cm}^{3}\right)$ & $A_{\mathrm{ev}}\left(\mathrm{m}^{2}\right)$ & $A_{\text {rec }}\left(\mathrm{m}^{2}\right)$ \\
\hline$n$-Pentane & 189 & 31.6 & 59.1 & 11.9 & 7.0 & 47.2 & 22.2 & 98.9 & 0.95 & 3.53 \\
\hline SES36 & 169 & 19.5 & 60.4 & 13.1 & 7.9 & 54.9 & 27.1 & 137.3 & 1.1 & 1.24 \\
\hline SES36 & 150 & 14.0 & 61.6 & 12.3 & 7.5 & 55.0 & 44.9 & 180.7 & 1.71 & 1.29 \\
\hline R245fa & 150 & 22.9 & 61.6 & 11.2 & 6.9 & 58.7 & 20.8 & 92.8 & 1.48 & 2.54 \\
\hline $\mathrm{R} 245 \mathrm{fa}$ & 109 & 12.8 & 63.9 & 7.7 & 4.9 & 50.3 & 59.9 & 0 & 4.02 & 2.73 \\
\hline $\mathrm{R} 134 \mathrm{a}$ & 85 & 17.1 & 65.1 & 5.6 & 3.6 & 59.7 & 37.2 & 0 & 2.7 & 1.53 \\
\hline
\end{tabular}

specific volume ratios, their effectiveness is reduced. Fig. 12 shows that the specific volume ratio remains acceptable for single-stage expansion only for R134a and R245fa (at low evaporating temperature). In the simulations, $\mathrm{R} 134 \mathrm{a}$ is therefore used with single-stage expansion architecture. Solkatherm and $n$-pentane are simulated with a double-stage expansion. R245fa is simulated with both architectures.

Fig. 13 shows the overall efficiency of the system with the four different fluids. A maximum appears in terms of evaporating temperature when the single-stage architecture is selected. This is explained by the very high underexpansion losses that reduce the expander effectiveness at high evaporating temperature. On the contrary, when using a two-stage expansion, the efficiency is limited by the critical temperature or by unrealistic working conditions such as very high specific volume ratios.

Solkatherm is the fluid showing the highest efficiency, with a maximum close to $8 \%$. It should however be noted that refrigeration compressors are not designed for temperatures higher than $150^{\circ} \mathrm{C}$, which might reduce their lifetime. If this limit is applied, the maximum overall efficiency is $7.5 \%$ for Solkatherm and 7\% for R245fa.

Additional parameters to the sole efficiency must be taken into account when comparing working fluids. Table 4 shows the more relevant cycle parameters for a few selected optimal points. The bold characters indicate the most advantageous value for each column. If Solkatherm is the most efficient fluid, it is also the one requiring the biggest expander, with a suction swept volume (in expander mode) of $180.7 \mathrm{~cm}^{3}$ for the second stage of expansion and an evaporating temperature of $150{ }^{\circ} \mathrm{C}$. R245fa on the contrary shows very advantageous swept volumes, which could reduce the cost of the system. $n$-Pentane must be run at very high temperature to show a good efficiency. Its required evaporator area is advantageous, but the required recuperator area is very high due to the low density and the very high pressure drops in the low-pressure vapor.

\subsection{Influence of the working conditions}

The developments proposed above were conducted for nominal conditions, defined in Section 4. However, the selection of these working conditions can have a non-negligible influence on the simulation results.

A parametric study is therefore performed to evaluate the influence of the nominal working conditions on the

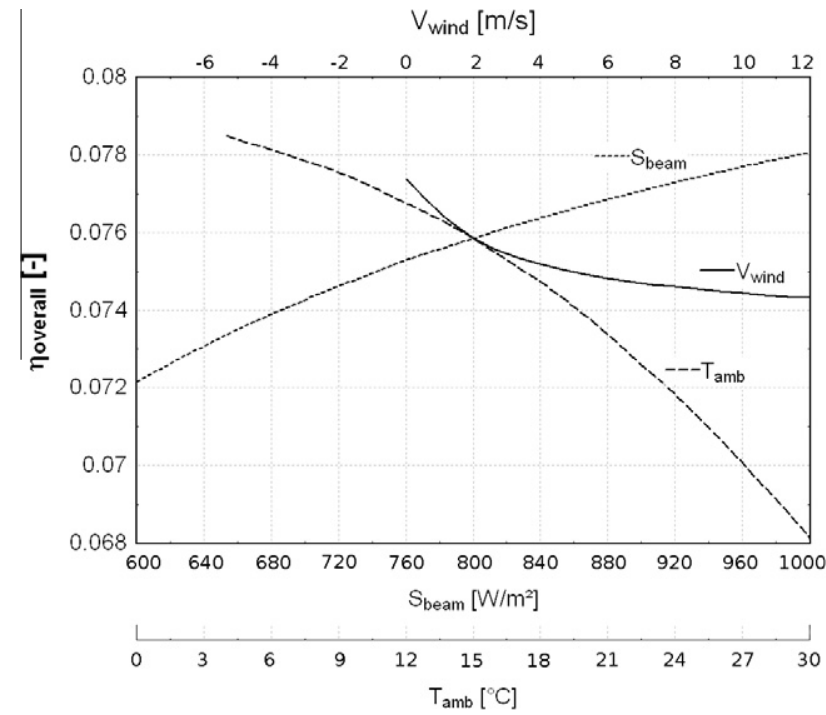

Fig. 14. Influence of the working conditions on the efficiency.

overall efficiency: this study is performed for the SES36 working fluid and an evaporating temperature imposed at $150{ }^{\circ} \mathrm{C}$ (third line in Table 4). Fig. 14 shows the influence of the wind speed, of the ambient temperature and of the solar beam insolation on the system performance. The influence of the wind speed is straightforward: the higher the speed, the lower the overall efficiency since the heat transfer coefficient from the collector to the ambient is increased. The same trend is stated for the beam insolation: a higher value makes the ambient losses of the collector proportionally smaller, and the overall efficiency is increased. The ambient temperature influences the cycle performance in two different ways: the ambient heat losses of the collector are increased with a lower ambient temperature, and the cycle efficiency is increased because of a lower condensing temperature. Fig. 14 shows that this second influence is predominant: for a $3-30{ }^{\circ} \mathrm{C}$ evolution of the ambient temperature, the collector efficiency is increased by $2 \%$, while the ORC cycle efficiency is decreased by $15 \%$, resulting in a $13 \%$ decrease of the overall efficiency.

\section{Conclusions}

Small-scale solar Organic Cycles are well adapted for remote off-grid areas of developing countries. Compared to the main competitive technology, the PV collector, Solar 
ORCs have an advantage of being manufacturable locally. They are also more flexible and allow the production of hot water as a by-product.

This work focused on the evaluation of the thermodynamic performance of the system. With conservative hypotheses, and real expander efficiency curves, it was shown that an overall electrical efficiency between $7 \%$ and $8 \%$ can be reached. This efficiency is a steady-state efficiency at a nominal working point. In order to evaluate the yearly energy output, a dynamic model is needed. In particular, the behavior of the storage tank should be modeled to perform a 1-year simulation.

It should be noted that these calculations were performed for off-the-shelf components, especially the expander, whose combined electro-mechanical efficiency did not exceed $60 \%$. Components specifically developed for the target applications (e.g. a high volume ratio expander, optimized for the ORC working fluid) could significantly increase the system performance.

The comparison between working fluids showed that the most efficient fluid is Solkatherm. However, it is also the fluid requiring the highest expander swept volumes, which increases the cost of the system. R245fa also shows a good efficiency and has the advantage of requiring much smaller equipment.

Even though part-load conditions were not simulated in the present work, the proposed model allows computing the performance of the system for a wide range of working and ambient conditions.

\section{References}

Badr, O., Probert, S.D., O'Callaghan, P., 1985. Performances of multivane expanders. Applied Energy 20, 207-234.

Bruno, J.C., Lopez-Villada, J., Letelier, E., Romera, S., Coronas, A., 2008. Modelling and optimisation of solar organic rankine cycle engines for reverse osmosis desalination. Applied Thermal Engineering 28, 2212-2226

Canada, S., Cohen, G., Cable, R., Brosseau, D., Price, H., 2004. Parabolic Trough Organic Rankine Cycle Solar Power Plant. In: DOE Solar Energy Technologies, Denver, Colorado.

Davidson, T.A., 1977. Design and Analysis of a $1 \mathrm{kw}$ Rankine Power Cycle, Employing a Multi-vane Expander, For Use with a Low Temperature Solar Collector, 61 leaves (61 fold.).

Delgado-Torres, A.M., Garcia-Rodriguez, L., 2007. Comparison of solar technologies for driving a desalination system by means of an organic Rankine cycle. Desalination 216, 276-291.

Delgado-Torres, A.M., Garcia-Rodriguez, L., 2010. Analysis and optimization of the low-temperature solar organic Rankine cycle (ORC). Energy Conversion and Management 51, 2846-2856.

Forristall, R., 2003. Heat Transfer Analysis and Modeling of a Parabolic Trough Solar Receiver Implemented in Engineering Equation Solver. NREL Technical Reports.

Hollands, K.G.T., Raithby, G.D., Konicek, L., 1975. Correlation equations for free convection heat transfer in horizontal layers of air and water. International Journal of Heat and Mass Transfer 18, 879884.

Hsieh, Y.Y., Lin, T.F., 2003. Evaporation heat transfer and pressure drop of refrigerant R-410A flow in a vertical plate heat exchanger. Journal of Heat Transfer - Transactions of the ASME 125, 852-857.
Incropera, F.P., DeWitt, D.P., 2002. Fundamentals of Heat and Mass Transfer, fifth ed. Wiley, New York.

Jing, L., Gang, P., Jie, J., 2010. Optimization of low temperature solar thermal electric generation with organic Rankine cycle in different areas. Applied Energy 87, 3355-3365.

Kane, M., 2002. Intégration et optimisation thermoéconomique \& environomique de centrales thermiques solaires hybrides. Ecole polytechnique Fédérale de Lausanne, Lausanne.

Kane, M., Larrain, D., Favrat, D., Allani, Y., 2003. Small hybrid solar power system. Energy 28, 1427-1443.

Klein, S.A., 2010. Engineering Equation Solver, F-Chart Software, Middleton, WI.

Lemort, V., Quoilin, S., Cuevas, C., Lebrun, J., 2009a. Testing and modeling a scroll expander integrated into an organic Rankine Cycle. Applied Thermal Engineering 29, 3094-3102.

Lemort, V., Quoilin, S., Pire, C., 2009b. Experimental investigation on a hermetic scroll expander. In: 7th International Conference on Compressors, Papiernička.

Lin, C., 2008. Feasibility of using power steering pumps in small-scale solar thermal electric power systems, S.B. Thesis, Dept. of Mechanical Engineering, MIT.

Manolakos, D., Papadakis, G., Kyritsis, S., Bouzianas, K., 2007. Experimental evaluation of an autonomous low-temperature solar Rankine cycle system for reverse osmosis desalination. Desalination 203, 366-374.

McMahan, A., 2006. Design and Optimization of Organic Rankine Cycle Solar Thermal Powerplants. MSc. Thesis, University of Wisconsin, Madison.

Monahan J., 1976. Development of a 1-kW, Organic Rankine Cycle Power Plant for remote applications. In: Intersociety Energy Conversion Engineering Conference, New York.

Orosz, M.S., Quoilin, S., Hemond, H., 2010. SORCE: A design tool for solar organic Rankine cycle systems in distributed generation applications. In: International Scientific Conference on Solar Heating, Cooling and Buildings.

Prabhu, E., National Renewable Energy Laboratory (US), 2006. Solar Trough Organic Rankine Electricity System (STORES). Stage 1. Power Plant Optimization and Economics November 2000-May 2005. National Renewable Energy Laboratory, Golden, Colo.

Probert, S.D.H.M., O'Callaghan, P.W., Bala, E., 1983. Design optimisation of a solar-energy harnessing system for stimulating an irrigation pump. Applied Energy, 15.

Quoilin, S., Lemort, V., 2009. Technological and economical survey of organic Rankine cycle systems. In: 5th European Conference on Economics and Management of Energy in Industry, Vilamoura, Portugal.

Quoilin, S., Lemort, V., Lebrun, J., 2010. Experimental study and modeling of an organic Rankine cycle using scroll expander. Applied Energy 87, 1260-1268.

Thonon, B., Vidil, R., Marvillet, C., 1995. Recent research and developments in plate heat-exchangers. Journal of Enhanced Heat Transfer 2, $149-155$.

Wang, J.L., Zhao, L., Wang, X.D., 2010a. A comparative study of pure and zeotropic mixtures in low-temperature solar Rankine cycle. Applied Energy 87, 3366-3373.

Wang, X.D., Zhao, L., Wang, J.L., Zhang, W.Z., Zhao, X.Z., Wu, W., 2010b. Performance evaluation of a low-temperature solar Rankine cycle system utilizing R245fa. Solar Energy 84, 353-364.

Witt, 2004. Air Cooled Condenser 550 RPM/Flying Bird 2. <http:// www.witthtp.com/literature.html $>$ (consulted on 2.12.10).

Wolpert, J.L., Riffat, S.B., 1996. Solar-powered Rankine system for domestic applications. Applied Thermal Engineering 16, 281-289.

Yamamoto, T., Furuhata, T., Arai, N., Mori, K., 2001. Design and testing of the organic Rankine cycle. Energy 26, 239-251.

Zanelli, R., Favrat, D., 1994. Experimental investigation of a hermetic scroll expander-generator. In: International Compressor Engineering Conference, Purdue. 